\title{
Effect of the Polydispersity of RBCs on the Recovery Rate of RBCs during the Removal of CPAs
}

\author{
Heyuan Qiao, ${ }^{1,2}$ Weiping Ding, ${ }^{1,2}$ Yuncong Ma, ${ }^{1,2}$ Sijie Sun, ${ }^{3}$ and Dayong Gao ${ }^{4}$ \\ ${ }^{1}$ Center for Biomedical Engineering, University of Science and Technology of China, Hefei, Anhui 230027, China \\ ${ }^{2}$ Department of Electronic Science and Technology, University of Science and Technology of China, Hefei, Anhui 230027, China \\ ${ }^{3}$ Department of Laboratory Medicine, University of Washington, Seattle, WA 98195, USA \\ ${ }^{4}$ Department of Mechanical Engineering, University of Washington, Seattle, WA 98195, USA
}

Correspondence should be addressed to Weiping Ding; wpdings@ustc.edu.cn

Received 28 July 2014; Revised 10 November 2014; Accepted 16 November 2014; Published 15 December 2014

Academic Editor: Chung-Min Liao

Copyright (C) 2014 Heyuan Qiao et al. This is an open access article distributed under the Creative Commons Attribution License, which permits unrestricted use, distribution, and reproduction in any medium, provided the original work is properly cited.

\begin{abstract}
In the process of removing cryoprotectants from cryopreserved blood, the theoretically optimal operating condition, which is based on the assumption that the distribution of red blood cells is uniform, is often used to reduce or even avoid the hypotonic damage to cells. However, due to the polydispersity of cells, the optimal condition is actually not reliable. In this study, based on the discrete concept developed in our previous work, the effect of the polydispersity on the recovery rate of cells in the dilution-filtration system was statistically investigated by assigning three random parameters, isotonic cell volume, cell surface area, and osmotically inactive cell volume, to cells in small units of blood. The results show that, due to the polydispersity, the real recovery rate deviates from the ideal value that is based on uniform distribution. The deviation significantly increases with the standard errors of cell parameters, and it can be also magnified by high cryoprotectant concentrations. Under the effect of polydispersity, the uniform distributionbased optimized blood or diluent flow rate is not perfect. In practice, one should adopt a more conservative blood or diluent flow rate so that the hypotonic damage to cells can be further reduced.
\end{abstract}

\section{Introduction}

The process of removing cryoprotectants (CPAs) is one of five important steps in the cryopreservation of red blood cells (RBCs) [1-8], where the damage to RBCs could happen due to the cell volume excursion induced by osmotic disequilibria. In the past decades, many methods have been proposed to improve the process, such as centrifugation [9-12], dialysis [13-15], and dilution-filtration [16, 17].

To optimize the methods mentioned above, many theoretical models have also been developed [18-25]. In these models, almost without exception, the three parameters of RBCs, such as the cell volume at isotonic condition, the cell surface area, and the osmotically inactive cell volume, were all assumed to be identical. Thus, the mean values measured from experiments were applied. In the centrifugation method, a single cell was often studied to get optimal conditions for all cells. In the dialysis-based or dilution-filtration method, the blood was divided into discrete units so that the effect of the randomness of RBCs entering the washing system on the osmotic damage to RBCs and the washing time necessary to remove CPAs could be investigated; however, the cells were still considered the same $[20,24,25]$. In fact, the polydispersity of RBCs, that is, the difference between RBCs, exists widely [26]. For example, the RBCs have different sizes and shapes not only at different growth stages $[27,28]$, but also at the same stage due to health, gender, and ethnic differences $[29,30]$. In abnormal subjects, the RBCs always have various differences compared to the ones in normal subjects (e.g., the volume distribution of RBCs would have a left shift peak in microcytic anemia patients or a right shift peak in pernicious anemia patients [31, 32]). In addition, the osmotically inactive cell volumes are also different in different growth stages for human RBCs [33-35], presenting in the form of random distributions [36,37]. Therefore, the reliability of these models only using the mean properties of cells to some extent is questionable. In practice, the polydispersity of RBCs could cause the failure in not only 


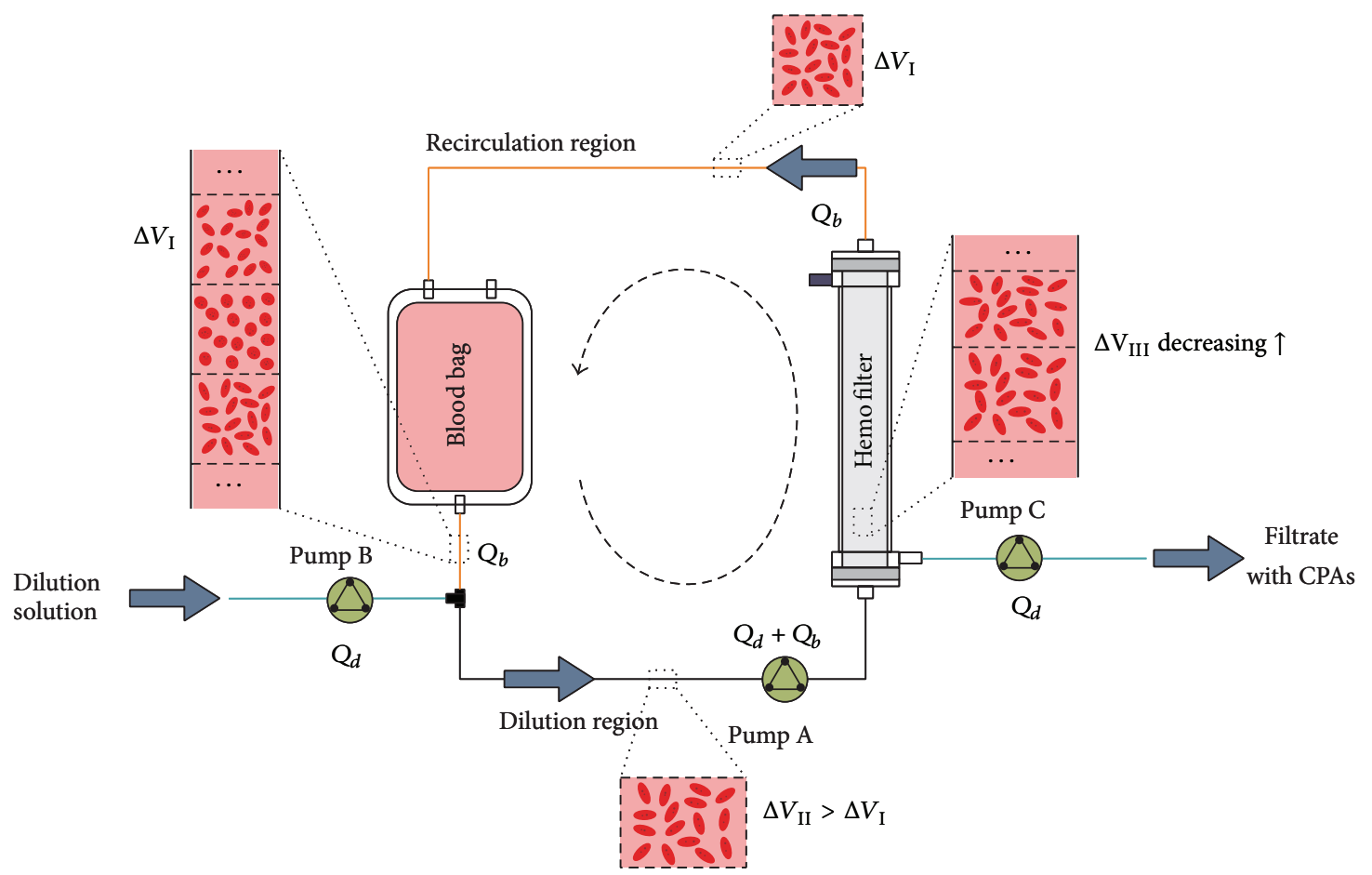

FIgure 1: Schematic of removing CPAs with the diluent-concentration system.

the accurate prediction of the recovery rate of RBCs but also the optimization of the washing process of CPAs. Thus, it needs to be noticed in intensive study.

In this work, the effect of the polydispersity of RBCs on the osmotic damage to RBCs or the recovery rate of RBCs in removing CPAs will be focused on. We will perform the study using the dilution-filtration system (Figure 1) in our previous work as an example to show the effect of polydispersity. The three characteristic parameters of RBCs as random variables will be integrated into the mass transfer equations. Then, the distribution of the cell maximum volumes under the polydispersity will be statistically analyzed, and the change of the distribution caused by the variation of the standard errors will be further studied. Finally, the effects of operating conditions, including cell swelling limits, cryoprotectant concentrations, and blood and diluent flow rates, will be discussed, and the safe operating condition under the effect of polydispersity will be given. To the best of our knowledge, the effect of the polydispersity of RBCs is for the first time considered in the cryopreservation of RBCs. Thus, our study could provide a strategy not only to predict more accurately the recovery rate of cells but also to search safer operating conditions for removing cryoprotectants. Furthermore, the thought in this work could be also extended to other washing systems to analyze the effect of the polydispersity of cells.

\section{Modeling}

2.1. Discrete Concept Revisited. In our previous work, a discrete concept was developed for the dialysis-based or dilution-filtration method to trace the volume variations of cells $[15,20,24]$. In the dilution-filtration method, the blood or red blood cell suspension to be washed is divided into a certain number of units. These units randomly enter the system, extend their volumes due to the dilution in the dilution region, restore their original volumes in the filter, go back to the blood bag, and wait to be selected into the system again (Figure 1). In the circulation of units, the CPA inside cells is transported out due to the decrease of the CPA outside cells induced by the dilution, filtered out of the hemofilter, and removed along with the filtrate, and the cells in units experience swelling and shrinkage.

The discretization makes it possible to trace the detailed information related to all units, including the volume of units, cell volumes, and solute concentrations inside and outside cells in units, to analyze whether the cells suffer osmotic damage and thus to statistically estimate the recovery rate of cells under a given operating condition. Compared to our previous work $[17,24,25]$, the novelty of this work is that we consider the effect of the polydispersity of RBCs on the optimized operating condition for safely removing CPAs.

In the dilution-filtration system, the mass transfer of cryoprotectants from inside to outside cells in any unit can be unified and calculated separately. By means of a similar derivation method in the literature [24], the volume of RBCs and the intracellular concentration of CPAs can be calculated by the classic two-parameter model [40, 41] and the extracellular concentration of CPAs can be obtained according to mass conservation:

$$
\begin{aligned}
\frac{d V_{c}}{d t}= & L_{p, c} A_{c} R T\left[\left(m_{n, 1}-m_{n, 2}\right)+\left(m_{s, 1}-m_{s, 2}\right)\right] \\
& -P_{s, c} A_{c} \overline{V_{s}}\left(m_{s, 1}-m_{s, 2}\right)
\end{aligned}
$$




$$
\begin{aligned}
\frac{d m_{s, 1}}{d t}= & -\frac{1+\overline{V_{s}} m_{s, 1}}{V_{c}-V_{b c}} \\
& \times\left[P_{s, c} A_{c}\left(m_{s, 1}-m_{s, 2}\right)\left(1+\overline{V_{s}} m_{s, 1}\right)+m_{s, 1} \frac{d V_{c}}{d t}\right]
\end{aligned}
$$

$$
\begin{aligned}
\frac{d m_{s, 2}}{d t}= & \frac{1+\overline{V_{s}} m_{s, 1}}{\Delta V-\alpha V_{c}} \\
& \times\left[\alpha P_{s, c} A_{c}\left(1+\overline{V_{s}} m_{s, 2}\right)\left(m_{s, 1}-m_{s, 2}\right)+\alpha m_{s, 2} \frac{d V_{c}}{d t}\right]
\end{aligned}
$$

$$
\begin{gathered}
m_{n, 1}=\frac{m_{n, 1}^{0}\left(V_{c}^{0}-V_{b c}-V_{s, 1}^{0}\right)}{V_{c}-V_{b c}-V_{s, 1}} \\
m_{n, 2}=\frac{m_{n, 2}^{0}\left(\Delta V^{0}-\alpha V_{c}^{0}-V_{s, 2}^{0}\right)}{\Delta V-\alpha V_{c}-V_{s, 2}},
\end{gathered}
$$

where $m_{s, 1}$ and $m_{s, 2}$ are CPA concentrations inside and outside RBCs, respectively $\left(\mathrm{mol} / \mathrm{kg} \mathrm{H}_{2} \mathrm{O}\right) ; m_{n, 1}$ and $m_{n, 2}$ are $\mathrm{NaCl}$ concentrations inside and outside RBCs, respectively (mol/kg $\mathrm{H}_{2} \mathrm{O}$ ); $V_{s, 1}$ and $V_{s, 2}$ are CPA volumes inside and outside RBCs, respectively $\left(\mu \mathrm{m}^{3}\right) . L_{p, c}(\mathrm{~m} / \mathrm{Pa} / \mathrm{s})$ and $P_{s, c}$ $(\mathrm{m} / \mathrm{s})$ are hydraulic permeability and solute permeability of the RBC membrane, respectively. $V_{c}$ is the RBC volume $\left(\mu \mathrm{m}^{3}\right), A_{c}$ is the cell membrane area $\left(\mu \mathrm{m}^{2}\right)$, and $V_{b c}\left(\mu \mathrm{m}^{3}\right)$ refers to the osmotically inactive volume of the cells at the isotonic condition $\left(V_{c}, A_{c}\right.$, and $V_{b c}$ are random variables). $R$ is the universal gas constant $(\mathrm{J} / \mathrm{mol} / \mathrm{K}) ; T$ is the absolute temperature $(\mathrm{K}) ; \overline{V_{s}}$ is the CPA partial molar volume $(\mathrm{l} / \mathrm{mol})$; and $\alpha$ is the cell density. $\Delta V$ is the volume of the blood units (it equals $\Delta V_{b}$ in the entrance region, $\Delta V_{b}+\Delta V_{d}$ in the dilution region, and $\Delta V_{b}$ in the recirculation region and decreases from $\Delta V_{b}+\Delta V_{d}$ to $\Delta V_{b}$ in the filter [24]). The superscript 0 denotes the previous time. The subscripts 1 and 2 denote inside and outside cells, respectively. The subscripts $b$ and $d$ denote blood and diluent, respectively. The subscripts $s$ and $n$ denote $\mathrm{CPA}$ and $\mathrm{NaCl}$, respectively.

In the blood bag, the mixing occurs because the number of blood units is very large. Under this situation, cell volume and intracellular solute concentrations can be described by (1), (2), and (4) whereas extracellular solute concentrations can be calculated by the following equations approximately [24]:

$$
\begin{gathered}
m_{s, 2}=\left(\sum \left\{\left(\Delta V^{0}-\alpha V_{c}^{0}-V_{s, 2}^{0}\right) m_{s, 2}^{0}\right.\right. \\
+\alpha\left[\left(V_{c}^{0}-V_{b c}-V_{s, 1}^{0}\right) m_{s, 1}^{0}\right. \\
\left.\left.\left.-\left(V_{c}-V_{b c}-V_{s, 1}\right) m_{s, 1}\right]\right\}\right) \\
\times\left(\sum\left(\Delta V_{b}-\alpha V_{c}-V_{s, 2}\right)\right)^{-1}, \\
m_{n, 2}=\frac{\sum\left(\Delta V_{b}^{0}-\alpha V_{c}^{0}-V_{s, 2}^{0}\right) m_{n, 2}^{0}}{\sum\left(\Delta V_{b}-\alpha V_{c}-V_{s, 2}\right)} .
\end{gathered}
$$

In the dilution-filtration system, at the dilution point (Figure 1), solute concentrations outside cells will change. Based on mass conservation, the relationships for them are as follows [24]:

$$
\begin{gathered}
\left(\Delta V_{b}-\alpha V_{c}^{I}-V_{s, 2}^{I}\right) m_{s, 2}^{I}=\left(\Delta V_{b}+\Delta V_{d}-\alpha V_{c}^{I I}-V_{s, 2}^{I I}\right) m_{s, 2}^{I I}, \\
\left(\Delta V_{b}-\alpha V_{c}^{I}-V_{s, 2}^{I}\right) m_{n, 2}^{I}+\Delta V_{d} m_{n, 2}^{d} \\
=\left(\Delta V_{b}+\Delta V_{d}-\alpha V_{c}^{I I}-V_{s, 2}^{I I}\right) m_{n, 2}^{I I}
\end{gathered}
$$

where the superscripts $I$ and $I I$ denote units before and after the dilution point, respectively, and $m_{n, 2}^{d}$ is the $\mathrm{NaCl}$ concentration in the dilution solution.

2.2. Polydispersity of RBCs. Once the blood is divided into a certain number of units, we need to assign three parameters of cells for all units (here, we assume that cells are the same in one unit but different in different units). Then, we have to face two questions: the first is what distributions the isotonic volume of cells, the surface area of cells, and the osmotically inactive volume of cells statistically meet, respectively; the second is what the correlation among these parameters is. In practice, the osmotically inactive volume of cells cannot be directly measured and can be only obtained by extrapolation in hypotonic expansion experiments [33]. In this work, to simplify the topic studied, we assume that it is independent of the other two parameters. As for the isotonic volume and surface area of cells, we theoretically confirm that they are subject to bivariate normal distribution, shown in the following paragraphs.

RBCs usually differ from each other in size and shape. This fact results in the disproportion between the isotonic volume of cells $\left(V_{\text {iso }}\right)$ and the surface area of cells $\left(A_{c}\right)$. In experiments, the isotonic volume of cells and the surface area of cells are both subjected to normal distribution; however, they are associated with some certain relationship. If the shape of RBCs is spherical, they should rigorously be subjected to the $2 / 3$ power relationship, but the shape of RBCs varies from sphere to oblate spheroid in different status. In the least squares analysis of volume versus area from the blood sample data of healthy adults, researchers concluded that they meet linear (with a correlation coefficient 0.969 in the literature [42] or 0.943 in the literature [43]) rather than $2 / 3$ power relationship $[42,43]$.

In our work, based on the pioneer work in the literature $[39,42]$, we assume that the joint distribution of the isotonic volume of cells and the surface area of cells is subjected to a bivariate normal distribution, as shown in Figure 2(a). The distribution parameters including mean value $\left(\mu_{v}\right.$ and $\left.\mu_{a}\right)$, standard error $\left(\sigma_{v}\right.$ and $\left.\sigma_{a}\right)$, and correlation coefficient $(r)$ are estimated by maximum likelihood estimation, which are presented below (the subscripts $v$ and $a$ indicate isotonic cell volume and surface area, resp.):

$$
\begin{aligned}
& \mu_{v}=\frac{\sum_{i=1}^{N} v_{i}}{N} \\
& \mu_{a}=\frac{\sum_{i=1}^{N} a_{i}}{N}
\end{aligned}
$$




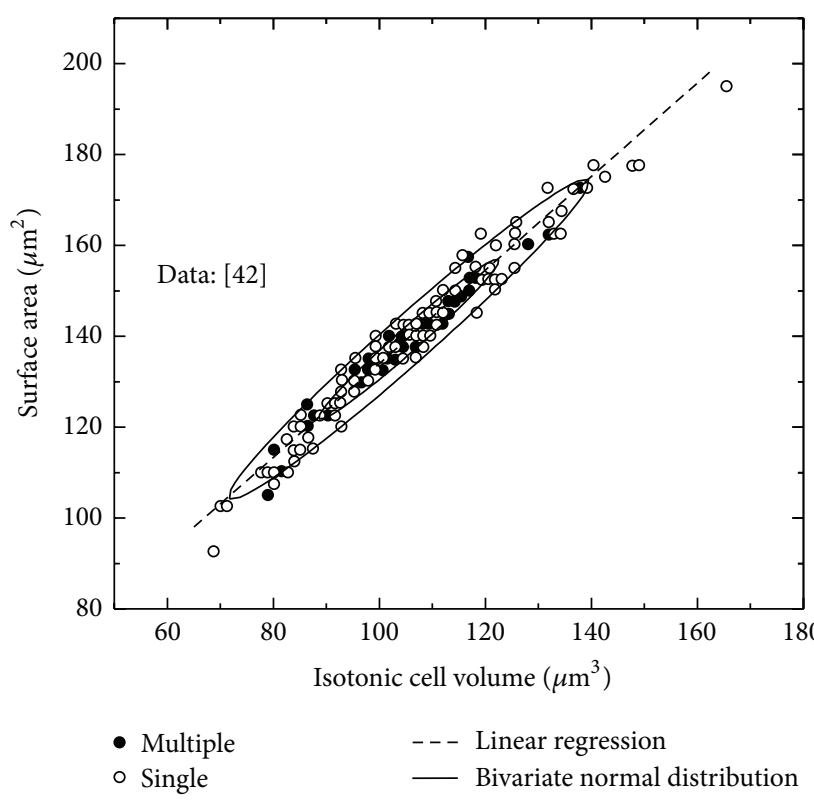

(a)

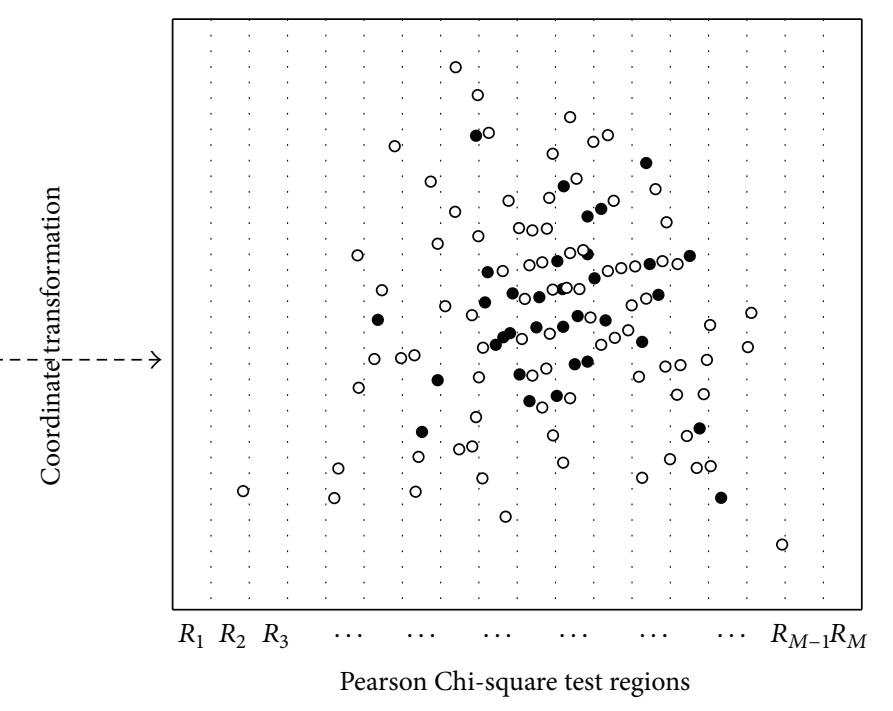

- Multiple

- Single

FIGURE 2: Relationship between isotonic cell volume and cell surface area (a) and Pearson Chi-square hypothesis test (b).

$$
\begin{gathered}
\sigma_{v}^{2}=\frac{\sum_{i=1}^{N}\left(v_{i}-\mu_{v}\right)^{2}}{N} \\
\sigma_{a}^{2}=\frac{\sum_{i=1}^{N}\left(a_{i}-\mu_{a}\right)^{2}}{N} \\
r=\frac{\sum_{i=1}^{N}\left(v_{i}-\mu_{v}\right)\left(a_{i}-\mu_{a}\right)}{\sqrt{\sum_{i=1}^{N}\left(v_{i}-\mu_{v}\right)^{2}} \sqrt{\sum_{i=1}^{N}\left(a_{i}-\mu_{a}\right)^{2}}}
\end{gathered}
$$

where $N$ is the number of observations. Then, the joint distribution probability density function (PDF) can be described in vector format as below:

$$
f(X)=\frac{1}{2 \pi \sqrt{|\Sigma|}} \exp \left[-\frac{1}{2}(X-\mu)^{T} \Sigma^{-1}(X-\mu)\right]
$$

where $X=\left[\begin{array}{l}v \\ a\end{array}\right]$ is the parameter vector, $\mu=\left[\begin{array}{l}\mu_{v} \\ \mu_{a}\end{array}\right]$ represents the mean vector, and $\Sigma=\left[\begin{array}{cc}\sigma_{v}^{2} & r \sigma_{v} \sigma_{a} \\ r \sigma_{v} \sigma_{a} & \sigma_{a}^{2}\end{array}\right]$ represents the covariance matrix.

In this work, the Pearson Chi-square test of goodness of fit is applied for hypothesis test of our bivariate normal distribution [44]. The null hypothesis is that the isotonic cell volume and surface area are subjected to bivariate normal distribution at $5 \%$ significance level.

First, we perform coordinate transformation for region division and frequency statistics. The inverse matrix of the covariance matrix $\left(\Sigma^{-1}\right)$ is diagonalized by orthogonal matrix $V$ :

$$
V^{T} \Sigma^{-1} V=D, \quad D=\left[\begin{array}{cc}
\lambda_{1} & 0 \\
0 & \lambda_{2}
\end{array}\right]
$$

where $D$ is the diagonalized covariance matrix. If we introduce $Y=\left[\begin{array}{c}v^{\prime} \\ a^{\prime}\end{array}\right]$ and set $X=V Y+\mu$, then we can get

$$
\begin{aligned}
f(Y) & =\frac{1}{2 \pi \sqrt{|\Sigma|}} \exp \left(-\frac{1}{2} Y^{T} D Y\right) \\
& =\frac{\sqrt{\lambda_{1} \lambda_{2}}}{2 \pi} \exp \left(-\frac{1}{2}\left(\lambda_{1} v^{\prime 2}+\lambda_{2} a^{\prime 2}\right)\right) .
\end{aligned}
$$

To calculate the Pearson statistic $\chi^{2}=\sum_{j=1}^{M}\left(\left(n_{j}-N P_{j}\right)^{2} / N P_{j}\right)$, we divide the $\left(v^{\prime}, a^{\prime}\right)$ plane into $M$ mutually disjoint regions $R_{1} \cdots R_{M}$ ( $n_{j}$ is the frequency statistics in each region, and $P_{j}$ is the theoretical probability in each region). $R_{1} \cdots R_{M}$ can be chosen as finite or infinite rectangle to simplify the calculation. Here, we use a serial of equidistant lines parallel to $y$-axis to divide the $\left(v^{\prime}, a^{\prime}\right)$ plane into different regions, which is shown in Figure 2(b) (the multiple points indicate that a same value of isotonic cell volume and surface area is observed multiple times (usually $\geq 3$ ) in the measurement).

Under the coordinate transformation, $n_{j}$ is counted in each region (multiple points counted as 3 ) and $P_{j}$ is calculated by

$$
\begin{aligned}
P_{j} & =\iint_{R_{j}} f(Y) d Y \\
& =\int_{h_{j-1}}^{h_{j}} \int_{-\infty}^{\infty} \frac{\sqrt{\lambda_{1} \lambda_{2}}}{2 \pi} \exp \left[-\frac{1}{2}\left(\lambda_{1} v^{\prime 2}+\lambda_{2} a^{\prime 2}\right)\right] d v^{\prime} d a^{\prime}
\end{aligned}
$$




$$
\begin{aligned}
= & \int_{h_{j-1}}^{h_{j}} \frac{\sqrt{\lambda_{1}}}{\sqrt{2 \pi}} \exp \left(-\frac{1}{2} \lambda_{1} v^{\prime 2}\right) d v^{\prime} \\
& \cdot \int_{-\infty}^{\infty} \frac{\sqrt{\lambda_{2}}}{\sqrt{2 \pi}} \exp \left(-\frac{1}{2} \lambda_{2} a^{\prime 2}\right) d a^{\prime} \\
= & \Phi\left(h_{j} \sqrt{\lambda_{1}}\right)-\Phi\left(h_{j-1} \sqrt{\lambda_{1}}\right),
\end{aligned}
$$

where $\Phi(x)$ represents the cumulative distribution function of the standard normal distribution.

Then, we can finally get the Chi-square critical value (the degree of freedom $d$ is calculated by the expression $d=$ $M-L-1$. In this study, $M=13$ is the number of different regions divided from the $\left(v^{\prime}, a^{\prime}\right)$ plane in Pearson Chi-square test and $L=5$ is the number of estimated parameters):

$$
\chi^{2}=\sum_{j=1}^{M} \frac{\left(n_{j}-N P_{j}\right)^{2}}{N P_{j}}<\chi_{0.05}^{2}(d) \text {. }
$$

The null hypothesis cannot be rejected at the $5 \%$ significance level and, thus, the isotonic cell volume and surface area are subjected to bivariate normal distribution with the estimated parameters. Therefore, the Pearson Chi-square test proves that the bivariate normal distribution is more suitable than the linear regression.

As for the osmotically inactive cell volume $\left(V_{b c}\right)$, though it may depend on the cell stage or cell aging, there are not any reliable data or literature to show its direct connections with the other two parameters. Here an independent normaldistributed random parameter is assumed in this work. The distribution of $V_{b c}$ is shown as follows:

$$
\begin{gathered}
\mu_{v b c}=\frac{\sum_{i=1}^{N} v_{b c_{i}}, \quad \sigma_{v b c}^{2}}{N}=\frac{\sum_{i=1}^{N}\left(v_{b c_{i}}-\mu_{v b c}\right)^{2}}{N}, \\
f\left(v_{b c}\right)=\frac{1}{\sqrt{2 \pi} \sigma_{v b c}} \exp \left[\frac{\left(v_{b c}-\mu_{v b c}\right)^{2}}{2 \sigma_{v b c}^{2}}\right],
\end{gathered}
$$

where the mean value $\left(\mu_{v b c}\right)$ and standard error $\left(\sigma_{v b c}\right)$ are derived from the several groups of fitted values listed in the literature [33].

2.3. Simulation Strategy. The purpose of this work is to theoretically and statistically study the effect of the polydispersity of RBCs in the process of removing cryoprotectants. The strategy is as follows. Firstly, the blood is divided into a certain number of small units, which are traced and controlled by a program code to randomly enter the washing system. Secondly, the three parameters of RBCs are generated by another program code and then randomly assigned to all units. Then, the above two-parameter equations are used to calculate the volume variations of cells and the concentration variations of CPAs in all units. Finally, the effect of the polydispersity on the recovery rate of RBCs under various situations is studied statistically.

In the simulation, the cryoprotectant was glycerol, the diluent was the isotonic solution only containing $\mathrm{NaCl}$
TABLE 1: Parameters used in this paper.

\begin{tabular}{lccc}
\hline Parameters & Units & Values & Reference \\
\hline Isotonic RBC volume, $V_{\text {iso }}$ & $\mu \mathrm{m}^{3}$ & $89.8 \pm 12.7^{*}$ & {$[33]$} \\
RBC surface area, $A_{c}$ & $\mu \mathrm{m}^{2}$ & $134.1 \pm 13.8^{*}$ & {$[33]$} \\
Osmotically inactive RBC & $\mu \mathrm{m}^{3}$ & $39.4 \pm 2.28^{*}$ & {$[33]$} \\
volume, $V_{b c}$ & $\mathrm{~m} / \mathrm{Pa} / \mathrm{s}$ & $1.74 \times 10^{-12}$ & {$[38]$} \\
Hydraulic permeability, $L_{p, c}$ & $\mathrm{~m} / \mathrm{s}$ & $6.61 \times 10^{-8}$ & {$[38]$} \\
Glycerol permeability, $P_{s, c}$ & $/$ & 0.943 & {$[39]$} \\
Correlation coefficient, $r$ & $\mathrm{~K}$ & 298 & \\
Absolute temperature, $T$ & ${ }^{*} V_{\text {iso }}, A_{c}$, and $V_{b c}$ are random variables (mean $\left.\pm \mathrm{STD}\right)$. &
\end{tabular}

(290 mOsm), and the blood was mimicked by the red blood cell suspension only containing $\mathrm{NaCl}$ and glycerol $(\mathrm{NaCl}$ : 290 mOsm; glycerol: 6500 mOsm; and hematocrit: 30\%). In the dilution-filtration system [17], the lumen volume of the plasma filter (Plasmflo AP-05H/L, ASAHI Co., Japan), the dilution region volume, and the recirculation region volume were $85 \mathrm{~mL}, 5 \mathrm{~mL}$, and $10 \mathrm{~mL}$, respectively (the diameter of the tubing was $4 \mathrm{~mm}$ ). Other parameters used are listed in Table 1 .

In this work, $200 \mathrm{~mL}$ of blood was divided into 5000 units so that the error caused by the division was less than $0.5 \%$ (the volume of units was $40 \mu \mathrm{L}$ and cells were considered identical in one unit but different in different units). Five thousand sets of random parameters (i.e., isotonic cell volume, cell surface area, and osmotically inactive volume) were generated by a program code and assigned to cells in 5000 units, subjecting to the distributions mentioned above. In calculation, units were randomly selected to enter the system and the cell volume changes in all units were traced, using another program code. If the cell maximum volume in one unit exceeds the upper tolerance limit (here, the upper tolerance limit for completely avoiding the hypotonic damage was set to $1.53 V_{\text {iso }}$ according to the literature [45]), all cells in this unit will be marked and regarded as dead. Then, the recovery rate of cells was statistically obtained. In this study, the program codes, developed in FORTRAN, were used to simulate the washing process and perform the statistical analysis. For each operating condition, the simulation was repeated 6 times and a mean value was used.

\section{Results and Discussion}

3.1. Statistical Distribution of the Maximum Volumes of the RBCs. In the dilution-filtration system, if all cells are assumed to be the same (i.e., the parameter distributions of cells are assumed to be uniform), when the optimized diluent flow rate is used, the maximum volumes of all cells are below the upper tolerance limit and the hypotonic damage to cells can be avoided completely (Figure 3(a)). However, due to the effect of the cell polydispersity, there are still some cells suffering from the hypotonic damage in practice (Figure 3(b); the standard errors of cell parameters are listed in Table 2). Moreover, the damage will increase with the standard error of no matter isotonic volume, surface area, 


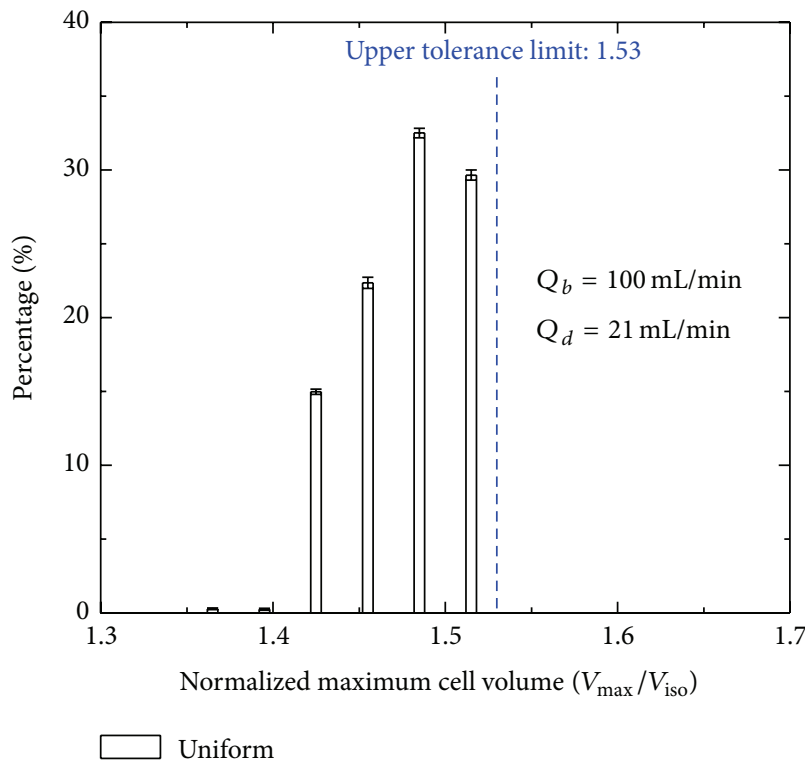

(a)

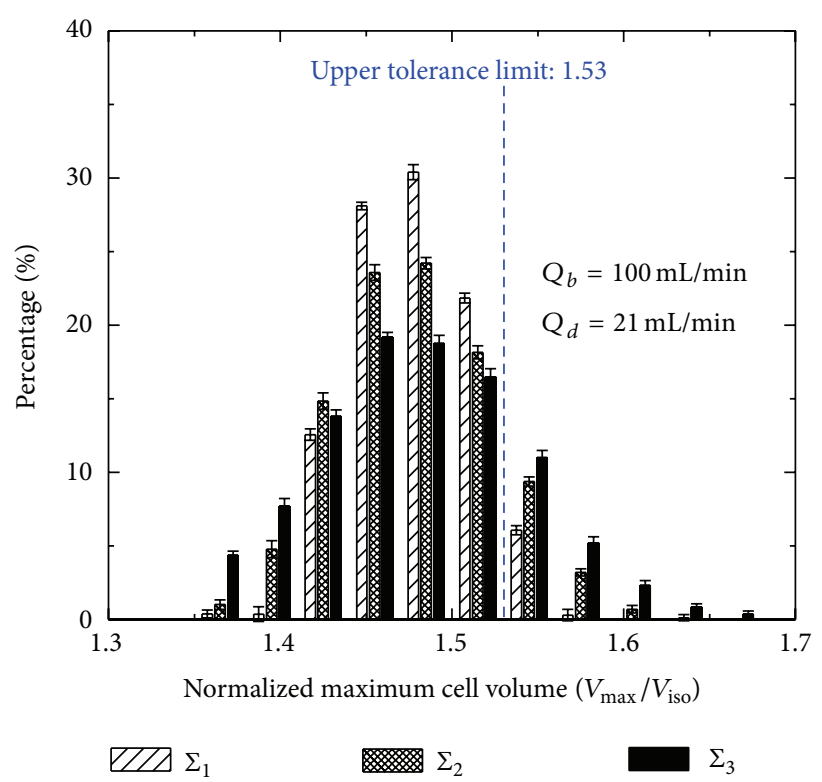

(b)

FIgURE 3: The comparison between cell maximum volume distributions under uniform (a) and random (b) parameters of cells.

TABLE 2: Standard errors of cell parameters used in the calculation.

\begin{tabular}{lccc}
\hline Standard error & Group 1 & Group 2 & Group 3 \\
\hline$\sigma_{i, V_{\text {iso }}}$ & $6.35 \mu \mathrm{m}^{3}$ & $12.7 \mu \mathrm{m}^{3}$ & $19.05 \mu \mathrm{m}^{3}$ \\
$\sigma_{i, A_{c}}$ & $6.9 \mu \mathrm{m}^{2}$ & $13.8 \mu \mathrm{m}^{2}$ & $20.7 \mu \mathrm{m}^{2}$ \\
$\sigma_{i, V_{b c}}$ & $1.14 \mu \mathrm{m}^{3}$ & $2.28 \mu \mathrm{m}^{3}$ & $3.42 \mu \mathrm{m}^{3}$ \\
$\sum_{i}$ & $\left\{\sigma_{1, V_{\text {iso }}}, \sigma_{1, A_{c}}, \sigma_{1, V_{b c}}\right\}$ & $\left\{\sigma_{2, V_{\text {iso }}}, \sigma_{2, A_{c}}, \sigma_{2, V_{b c}}\right\}$ & $\left\{\sigma_{3, V_{\text {iso }}}, \sigma_{3, A_{c}}, \sigma_{3, V_{b c}}\right\}$ \\
\hline
\end{tabular}

TABLE 3: Cell mortality rates under different standard errors.

\begin{tabular}{lccc}
\hline Standard error & Group 1 & Group 2 & Group 3 \\
\hline$\sigma_{i, V_{\text {iso }}}$ & $0.78 \%$ & $3.06 \%$ & $5.54 \%$ \\
$\sigma_{i, A_{c}}$ & $1.56 \%$ & $3.62 \%$ & $5.82 \%$ \\
$\sigma_{i, V_{b c}}$ & $4.22 \%$ & $9.20 \%$ & $13.79 \%$ \\
$\sum_{i}$ & $6.36 \%$ & $13.14 \%$ & $19.72 \%$ \\
\hline
\end{tabular}

or inactive volume (Figure 4 and Table 3 ). The effect of the osmotically inactive cell volume is relatively more significant. In addition, our results also show that the distribution of the cell maximum volume is normal under the condition of the polydispersity (Figure 4). Here, the optimized diluent flow rate is an allowable value set by system, which makes the maximum volume of the RBCs very close to the upper tolerance limit and is kept constant in all cycles.

Having established that the polydispersity results in the optimized condition deviating from the actual expectation, we wonder how to improve the condition to minimize the effect of the polydispersity. For the dilution-filtration system, an effective method is to set a small or conservative cell-swelling limit in searching the optimized diluent flow rate (Figure 5(a)). By doing so, the distribution of the cell maximum volume will move left, as shown in Figure 5(b), and the recovery rate of cells will increase. For example, when the blood flow rate is $100 \mathrm{~mL} / \mathrm{min}$, if the three standard errors are $12.7 \mu \mathrm{m}^{3}, 13.8 \mu \mathrm{m}^{2}$, and $2.28 \mu \mathrm{m}^{3}$, respectively, and the expected recovery rate is higher than $95 \%$, the cell swelling limit should be smaller than $1.50 V_{\text {iso }}$, instead of $1.53 V_{\text {iso }}$ (Figure 5(a)). Corresponding to the change, the optimized diluent flow rate should be smaller than $19 \mathrm{~mL} / \mathrm{min}$ (Figure 5(b)).

\subsection{Effects of the RBC Polydispersity under Various Initial} $C P A$ Concentrations. Since the polydispersity can cause the decrease in the recovery rate of cells, even if the optimized condition is used, it is important to understand in practice when the effect of the polydispersity becomes significant. Our results show that the polydispersity decreases the recovery rates of cells, especially when the initial CPA concentration is high (the high concentration of CPAs causes the large volume change of cells in cycles and then the effect of the polydispersity is accumulated). Moreover, the difference of the recovery rates of cells between uniform and random distributions also increases with the initial CPA concentration (Figure 6). For example, when the three standard errors are $12.7 \mu \mathrm{m}^{3}, 13.8 \mu \mathrm{m}^{2}$, and $2.28 \mu \mathrm{m}^{3}$, respectively, if the CPA concentration added to blood at the beginning of cryopreservation is increased from $5.5 \mathrm{~mol} / \mathrm{kg} \mathrm{H}_{2} \mathrm{O}$ to 


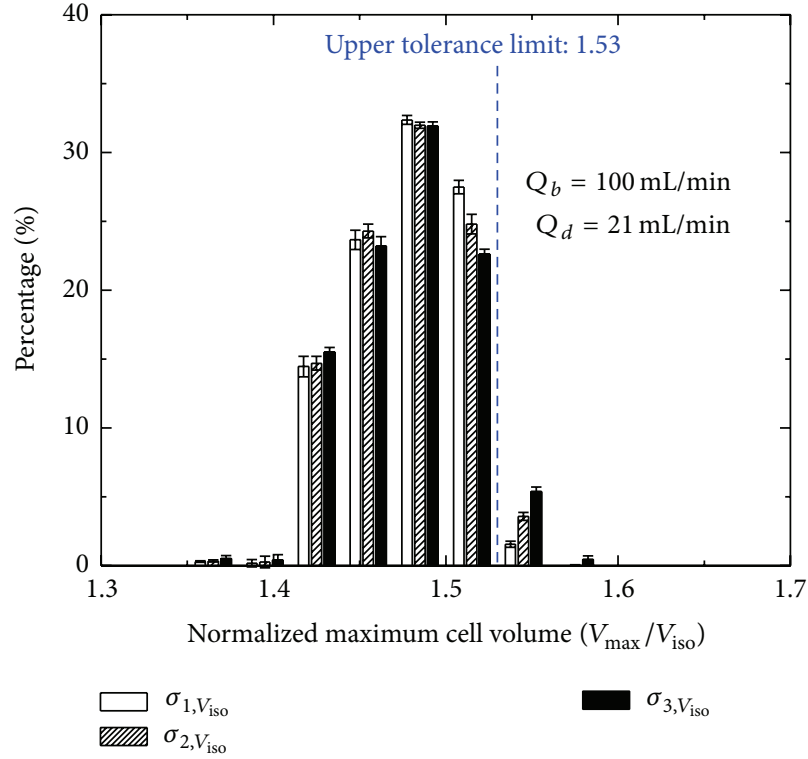

(a)

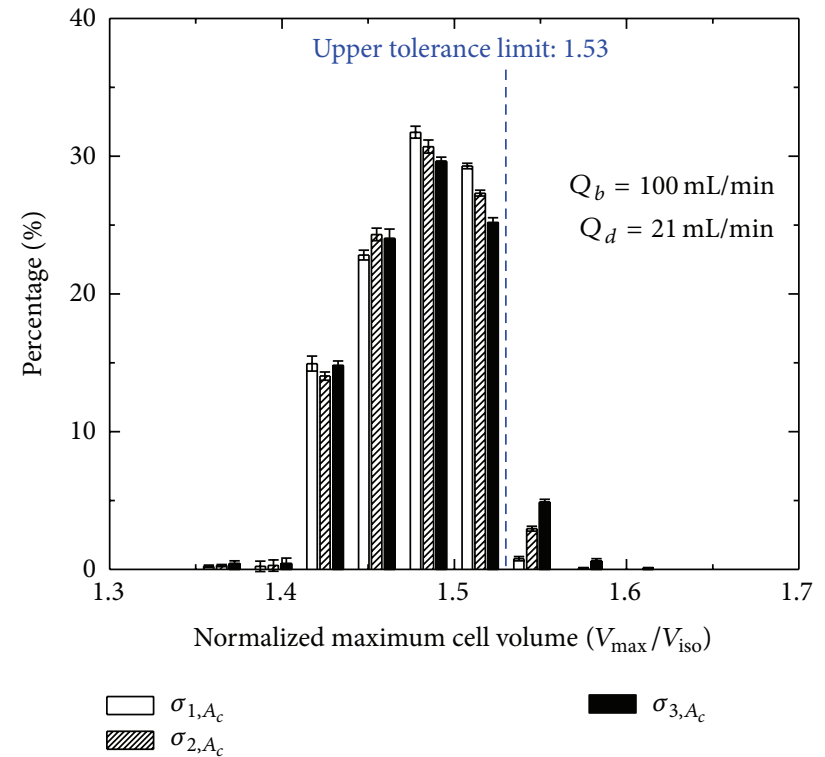

(b)

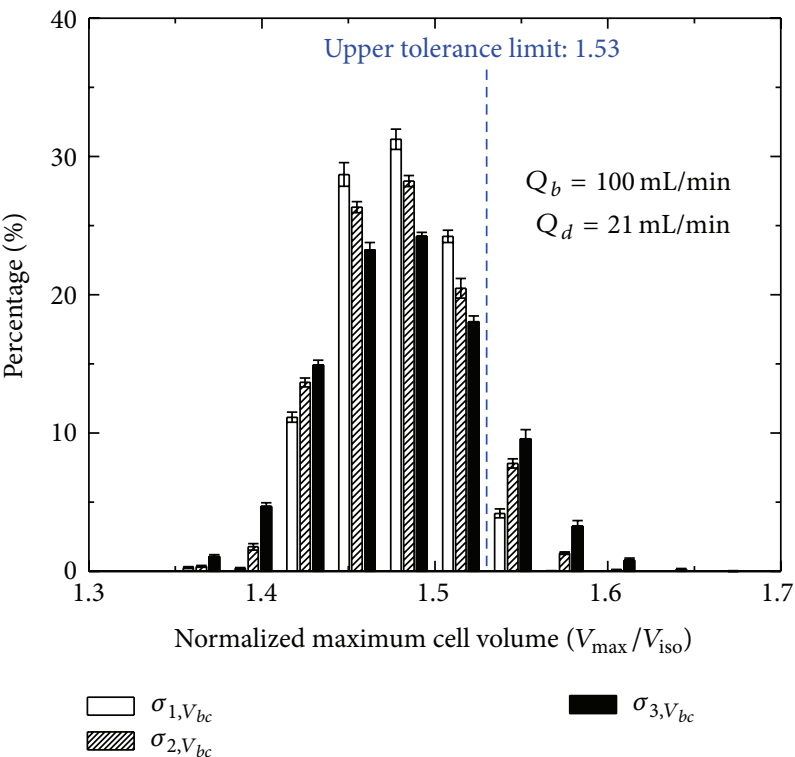

(c)

FIGURE 4: The effects of standard errors of isotonic cell volume (a), cell surface area (b), and osmotically inactive cell volume (c) on distributions of cell maximum volumes.

$6.5 \mathrm{~mol} / \mathrm{kg} \mathrm{H}_{2} \mathrm{O}$, the difference will increase from $0.38 \%$ to $13.14 \%$. Therefore, a more conservative cell-swelling limit should be set for the dilution-filtration system in practice when a higher CPA concentration needs to be removed.

\subsection{Effects of the RBC Polydispersity under Various Blood and} Diluent Flow Rates. In the dilution-filtration system, diluent and blood flow rates are two controllable factors to reduce the hypotonic damage to cells. Under the assumption of uniform distribution, for a fixed diluent flow rate, the ideal recovery rate of cells first remains 0 , then increases approximately linearly, and finally keeps 1 as the blood flow rate increases
(Figure 7(a); the upper inflection point is called the uniform distribution-based optimal blood flow rate for a fixed diluent flow rate). However, due to the polydispersity, the change trend of the real recovery rate of cells presents a smooth curve rather than a broken line: when the blood flow rate is larger, the real recovery rate is less than the ideal one; when the blood flow rate is lower, the result is just the opposite (Figure 7). Similar to the effect of polydispersity under various blood flow rates, the deviation between ideal and real recovery rates of cells also exists under various diluent flow rates (Figure 7(b); the lower inflection point is called the uniform distribution-based optimal diluent flow 


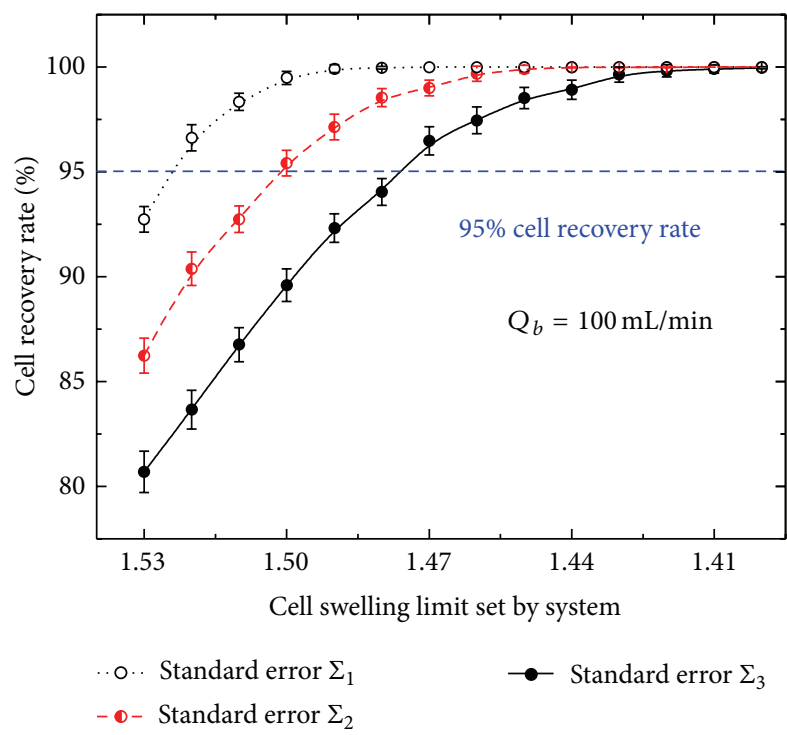

(a)

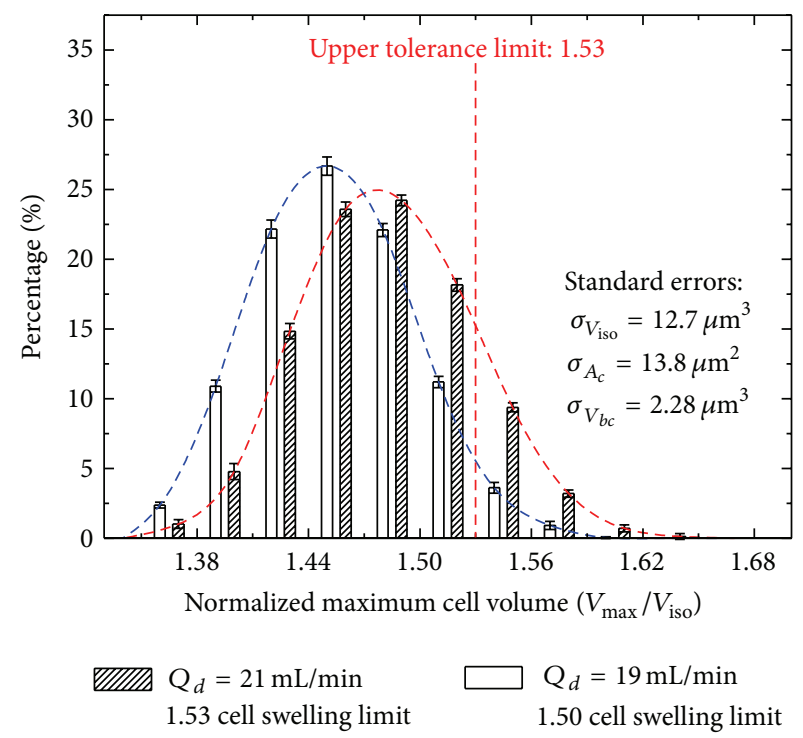

(b)

FIGURE 5: The comparisons of cell recovery rates (a) and cell maximum volume distributions (b) under various cell swelling limits set by system.

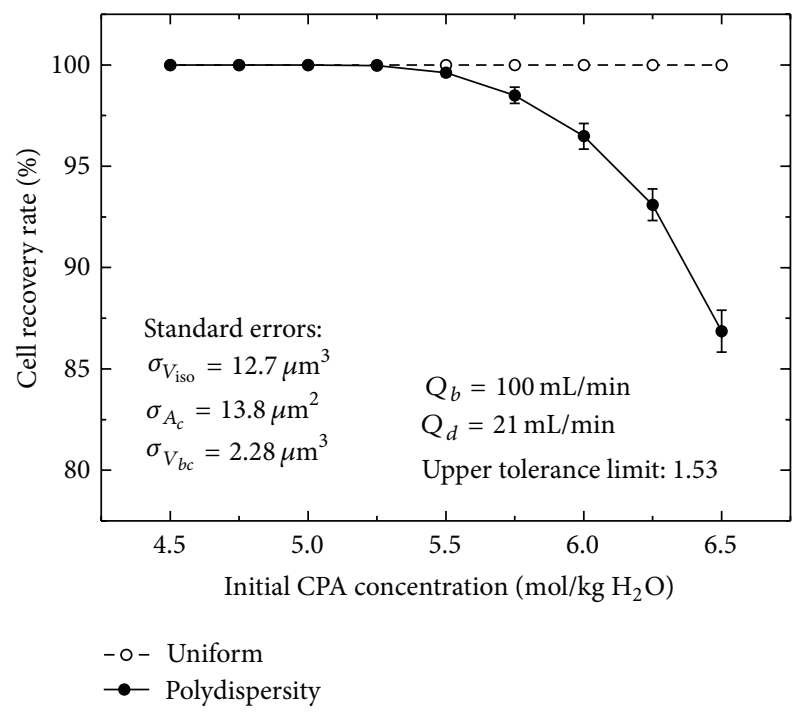

FIGURE 6: The effect of the cell polydispersity on the recovery rate of cells under various initial CPA concentrations.

rate for a fixed blood flow rate). Our results indicate that the uniform distribution-based optimal blood or diluent flow rate is inappropriate and can still cause cell loss because of the polydispersity of cells. Therefore, in practice, to reduce the effect of the polydispersity of cells, a more conservative condition (a higher blood flow rate or a lower diluent flow rate) should be used so that the expected recovery rate of cells can be obtained. In this work, a basic picture on the recovery rates of cells under various blood and diluent flow rates is shown in Figure 8, taking into account the polydispersity of cells. The picture clearly shows the nonlinear trend of the recovery rate of cells for a fixed blood or diluent flow rate and it can be used to practically guide the washing process of CPAs using the dilution-filtration system.

\section{Conclusions}

In this work, we provide a strategy to statistically study the effect of the polydispersity of RBCs on the recovery rate of RBCs in removing CPAs from cryopreserved blood by assigning three random parameters to all cells, isotonic volume, surface area, and inactive volume. To confirm the effect of the polydispersity, the deviation between ideal and real recovery rates of RBCs in the dilution-filtration system proposed in our previous work is investigated. The results show that due to the polydispersity, the real recovery rate deviates from the ideal one; moreover, the deviation significantly increases with the standard errors of cell parameters (if the three standard errors vary from $6.35 \mu \mathrm{m}^{3}, 6.9 \mu \mathrm{m}^{2}$, and $1.14 \mu \mathrm{m}^{3}$ to $19.05 \mu \mathrm{m}^{3}, 20.7 \mu \mathrm{m}^{2}$, and $3.42 \mu \mathrm{m}^{3}$, resp., the deviation will increase from $6.36 \%$ to $19.72 \%$ ). The high concentration of CPAs added at the beginning of the cryopreservation process can magnify the effect of polydispersity. If the concentration is increased from $5.5 \mathrm{~mol} / \mathrm{kg} \mathrm{H}_{2} \mathrm{O}$ to $6.5 \mathrm{~mol} / \mathrm{kg} \mathrm{H}_{2} \mathrm{O}$, when the three standard errors are $12.7 \mu \mathrm{m}^{3}, 13.8 \mu \mathrm{m}^{2}$, and $2.28 \mu \mathrm{m}^{3}$, respectively, the deviation will increase from $0.38 \%$ to $13.14 \%$. Under the effect of polydispersity, the uniform distribution-based optimized blood or diluent flow rate is not perfect. In practice, one still needs to adopt a more conservative condition, that is, a blood flow rate higher than the optimized blood flow rate or a diluent flow rate lower than the optimized diluent flow rate, so that the expected recovery rate of cells can be obtained.

In this study, we only theoretically study the effect of the polydispersity of RBCs. To validate the simulation with 


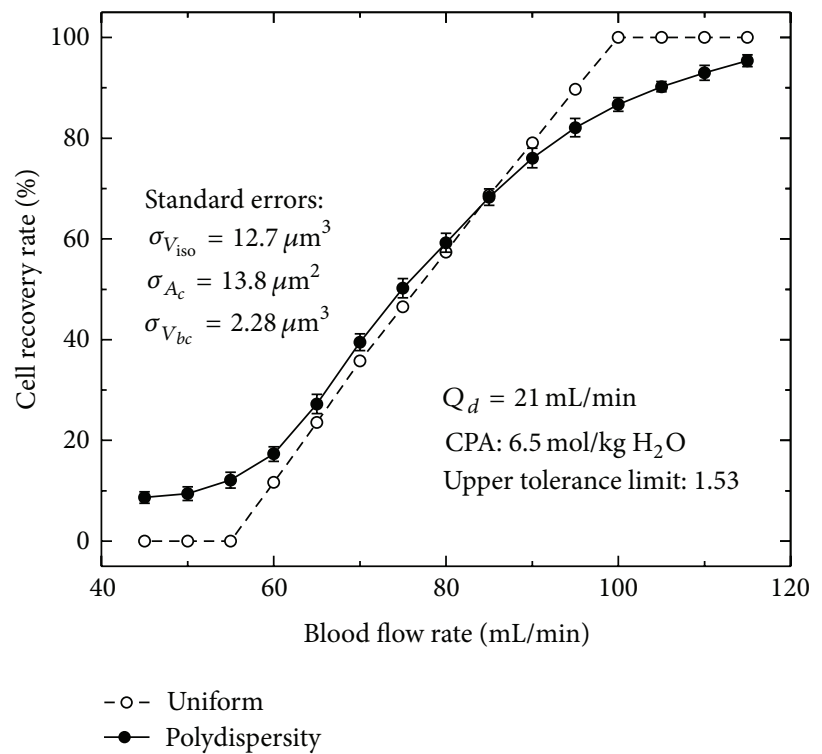

(a)

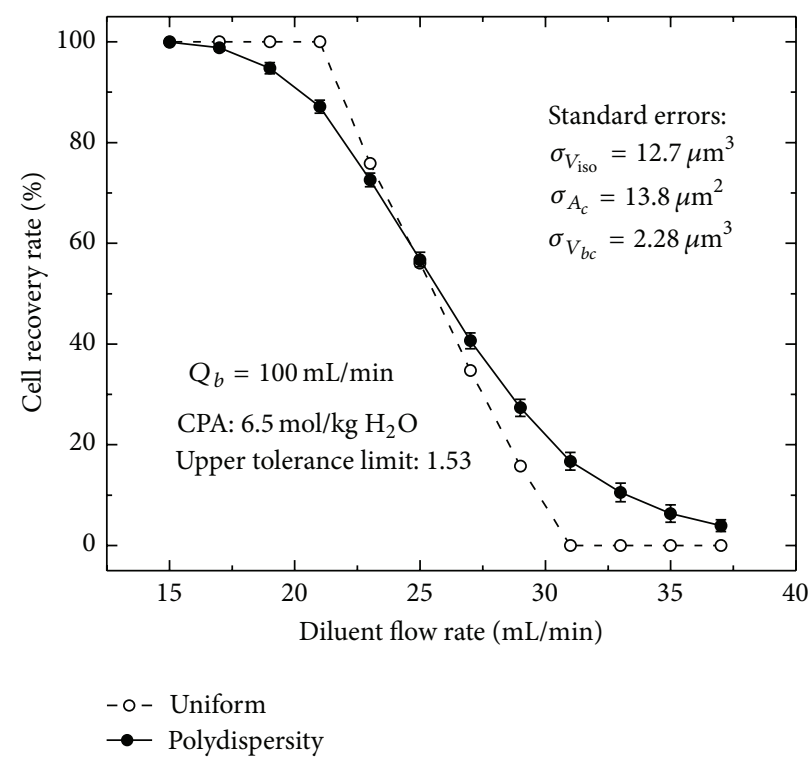

(b)

FIGURE 7: The effect of the cell polydispersity on the recovery rate of cells under various blood flow rates (a) or diluent flow rates (b).

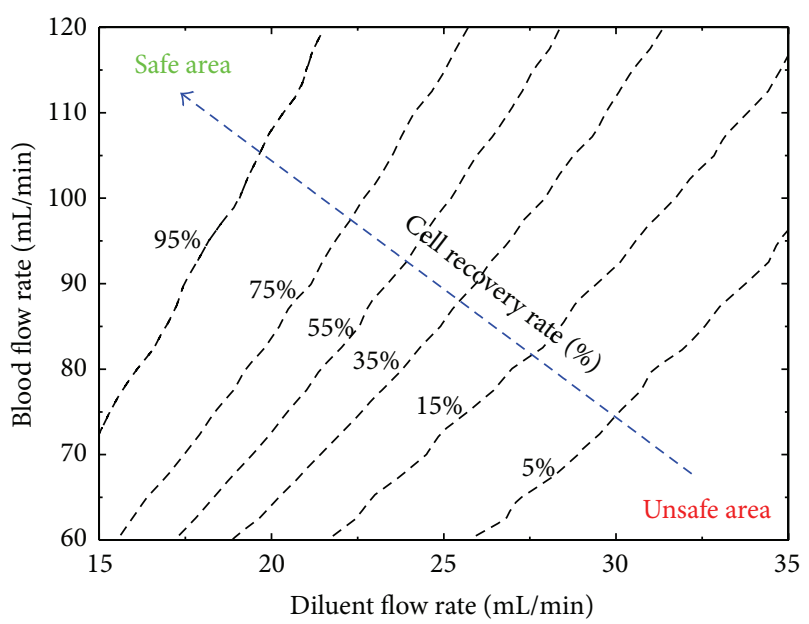

FIGURE 8: The recovery rates of cells under various blood and diluent flow rates.

the measured recovery rate of RBCs, one should first experimentally determine the distributions of the three parameters of RBCs, then measure the recovery rate of RBCs after using the dilution-filtration system under a given operating condition, and finally compare the measured recovery rate of RBCs with the theoretical value. In practice, to establish a customized filtration-dilution system by considering the polydispersity of RBCs as well as the associated optimal blood and diluent flow rates, an extra storage for the table that includes the precalculated optimal operating conditions needs to be embedded into the system. In addition, it should be noted that the strategy developed here could be used for not only the cryoprotectant unloading process but also the cryoprotectant loading process.

\section{Conflict of Interests}

The authors declare that they have no competing interests.

\section{Acknowledgments}

This work was supported by the Fundamental Research Funds for the Central Universities of China (WK2100000001), the Specialized Research Fund for the Doctoral Program of Higher Education of China (WJ2100230004), and the Natural Science Foundation of Anhui Province (BJ2100230008).

\section{References}

[1] B. Calmels, P. Houzé, J.-C. Hengesse, T. Ducrot, C. Malenfant, and C. Chabannon, "Preclinical evaluation of an automated closed fluid management device: cytomate, for washing out DMSO from hematopoietic stem cell grafts after thawing," Bone Marrow Transplantation, vol. 31, no. 9, pp. 823-828, 2003.

[2] R. Syme, M. Bewick, D. Stewart, K. Porter, T. Chadderton, and S. Glück, "The role of depletion of dimethyl sulfoxide before autografting: on hematologic recovery, side effects, and toxicity," Biology of Blood and Marrow Transplantation, vol. 10, no. 2, pp. 135-141, 2004.

[3] C. R. Valeri, G. Ragno, P. van Houten et al., "Automation of the glycerolization of red blood cells with the high-separation bowl in the Haemonetics ACP 215 instrument," Transfusion, vol. 45, no. 10, pp. 1621-1627, 2005.

[4] H. T. Meryman, "Cryopreservation of living cells: principles and practice," Transfusion, vol. 47, no. 5, pp. 935-945, 2007.

[5] G. J. Ruiz-Delgado, C. Mancías-Guerra, E. L. Tamez-Gómez et al., "Dimethyl sulfoxide-induced toxicity in cord blood stem cell transplantation: report of three cases and review of the literature," Acta Haematologica, vol. 122, no. 1, pp. 1-5, 2009. 
[6] G. B. Quan, Y. Han, M. X. Liu et al., "Addition of oligosaccharide decreases the freezing lesions on human red blood cell membrane in the presence of dextran and glucose," Cryobiology, vol. 62, no. 2, pp. 135-144, 2011.

[7] K. A. Almansoori, V. Prasad, J. F. Forbes et al., "Cryoprotective agent toxicity interactions in human articular chondrocytes," Cryobiology, vol. 64, no. 3, pp. 185-191, 2012.

[8] V. Pallotta, G. M. D’Amici, A. D’Alessandro, R. Rossetti, and L. Zolla, "Red blood cell processing for cryopreservation: from fresh blood to deglycerolization," Blood Cells, Molecules, and Diseases, vol. 48, no. 4, pp. 226-232, 2012.

[9] C. R. Valeri, G. L. E. Ragno, R. Pivacek et al., "A multicenter study of in vitro and in vivo values in human RBCs frozen with 40-percent (wt/vol) glycerol and stored after deglycerolization for 15 days at 4 degrees C in AS-3: assessment of RBC processing in the ACP 215 (vol 41, pg 933, 2001)," Transfusion, vol. 42, no. 12, p. 1618, 2001.

[10] C. C. M. Lelkens, F. Noorman, J. G. Koning et al., "Stability after thawing of RBCs frozen with the high- and low-glycerol method," Transfusion, vol. 43, no. 2, pp. 157-164, 2003.

[11] N. Bandarenko, J. Cancelas, E. L. Snyder et al., "Successful in vivo recovery and extended storage of additive solution (AS)-5 red blood cells after deglycerolization and resuspension in AS-3 for 15 days with an automated closed system," Transfusion, vol. 47, no. 4, pp. 680-686, 2007.

[12] R. E. Lusianti, J. D. Benson, J. P. Acker, and A. Z. Higgins, "Rapid removal of glycerol from frozen-thawed red blood cells," Biotechnology Progress, vol. 29, no. 3, pp. 609-620, 2013.

[13] A. Zelman, D. Gisser, D. Smith, and R. Stephen, "Dialysis processing of cryopreserved red blood cells," in Synthetic Membranes: Hyper- and Ultrafiltration Uses, vol. 2, pp. 109-118, 1981.

[14] F. Castino and S. R. Wickramasinghe, "Washing frozen red blood cell concentrates using hollow fibres," Journal of Membrane Science, vol. 110, no. 2, pp. 169-180, 1996.

[15] W. Ding, J. Yu, E. Woods, S. Heimfeld, and D. Gao, "Simulation of removing permeable cryoprotective agents from cryopreserved blood with hollow fiber modules," Journal of Membrane Science, vol. 288, no. 1-2, pp. 85-93, 2007.

[16] F. Arnaud, E. Kapnik, and H. T. Meryman, "Use of hollow fiber membrane filtration for the removal of DMSO from platelet concentrates," Platelets, vol. 14, no. 3, pp. 131-137, 2003.

[17] X. Zhou, Z. Liu, Z. Shu et al., "A dilution-filtration system for removing cryoprotective agents," Journal of Biomechanical Engineering, vol. 133, no. 2, Article ID 021007, 2011.

[18] D. Y. Gao, J. Liu, C. Liu et al., "Prevention of osmotic injury to human spermatozoa during addition and removal of glycerol," Human Reproduction, vol. 10, no. 5, pp. 1109-1122, 1995.

[19] J. A. Gilmore, J. Liu, D. Y. Gao, and J. K. Critser, “Determination of optimal cryoprotectants and procedures for their addition and removal from human spermatozoa," Human Reproduction, vol. 12, no. 1, pp. 112-118, 1997.

[20] W. Ding, S. Sun, C. Liu, S. Heimfeld, and D. Gao, "A random method for theoretical estimation of RBC osmotic damage in removing CPAs from cryopreserved blood with hollow fiber modules: closed-loop blood flow mode," Journal of Membrane Science, vol. 360, no. 1-2, pp. 17-25, 2010.

[21] W. Ding, X. Zhou, S. Heimfeld, J.-A. Reems, and D. Gao, "A steady-state mass transfer model of removing CPAs from cryopreserved blood with hollow fiber modules," Journal of Biomechanical Engineering, vol. 132, no. 1, 2010.
[22] J. D. Benson, C. C. Chicone, and J. K. Critser, "A general model for the dynamics of cell volume, global stability, and optimal control," Journal of Mathematical Biology, vol. 63, no. 2, pp. 339359, 2011.

[23] J. D. Benson, A. J. Kearsley, and A. Z. Higgins, "Mathematical optimization of procedures for cryoprotectant equilibration using a toxicity cost function," Cryobiology, vol. 64, no. 3, pp. 144-151, 2012.

[24] L. Gong, W. Ding, Y. Ma, S. Sun, G. Zhao, and D. Gao, "Statistical estimation of red blood cell osmotic damage during cryoprotective agent removal from cryopreserved blood," Biopreservation and Biobanking, vol. 11, no. 5, pp. 299-308, 2013.

[25] H. Y. Qiao, W. P. Ding, S. J. Sun, L. Q. Gong, and D. Y. Gao, "Theoretical optimization of the removal of cryoprotective agents using a dilution-filtration system," Biomedical Engineering Online, vol. 13, article 120, 2014.

[26] Y. M. Alomari, S. N. H. Sheikh Abdullah, R. Zaharatul Azma, and K. Omar, "Automatic detection and quantification of WBCs and RBCs using iterative structured circle detection algorithm," Computational and Mathematical Methods in Medicine, vol. 2014, Article ID 979302, 17 pages, 2014.

[27] T. Shinozuka, Y. Miyata, S. Takei et al., "Changes in En(a-) human red blood cell membranes during in vivo ageing," Mechanisms of Ageing and Development, vol. 86, no. 1, pp. 27-37, 1996.

[28] S. C. Gifford, T. Yoshida, S. S. Shevkoplyas, and M. W. Bitensky, "A high-resolution, double-labeling method for the study of in vivo red blood cell aging," Transfusion, vol. 46, no. 4, pp. 578$588,2006$.

[29] I. Sincer, A. Zorlu, M. B. Yilmaz et al., "Relationship between red cell distribution width and right ventricular dysfunction in patients with chronic obstructive pulmonary disease," Heart and Lung: Journal of Acute and Critical Care, vol. 41, no. 3, pp. 238-243, 2012.

[30] S. K. Zalawadiya, V. Veeranna, S. S. Panaich, L. Afonso, and J. K. Ghali, "Gender and ethnic differences in red cell distribution width and its association with mortality among low risk healthy united state adults," The American Journal of Cardiology, vol. 109, no. 11, pp. 1664-1670, 2012.

[31] J. D. Bessman and R. K. Johnson, "Erythrocyte volume distribution in normal and abnormal subjects," Blood, vol. 46, no. 3, pp. 369-379, 1975.

[32] J. Guitard, D. Ribes, N. Kamar et al., "Predictive factors for anemia within the first year after orthotopic liver transplantation," Transplantation Proceedings, vol. 38, no. 7, pp. 2342-2345, 2006.

[33] O. Linderkamp and H. J. Meiselman, "Geometric, osmotic, and membrane mechanical properties of density-separated human red cells," Blood, vol. 59, no. 6, pp. 1121-1127, 1982.

[34] A. K. Solomon, M. R. Toon, and J. A. Dix, "Osmotic properties of human red cells," Journal of Membrane Biology, vol. 91, no. 3, pp. 259-273, 1986.

[35] S. C. Gifford, J. Derganc, S. S. Shevkoplyas, T. Yoshida, and M. W. Bitensky, "A detailed study of time-dependent changes in human red blood cells: from reticulocyte maturation to erythrocyte senescence," British Journal of Haematology, vol. 135, no. 3, pp. 395-404, 2006.

[36] C. J. Hunt, S. E. Armitage, and D. E. Pegg, "Cryopreservation of umbilical cord blood: 1. Osmotically inactive volume, hydraulic conductivity and permeability of $\mathrm{CD}^{+} 4^{+}$cells to dimethyl sulphoxide," Cryobiology, vol. 46, no. 1, pp. 61-75, 2003.

[37] I. L. Lisovskaya, I. M. Shcherbachenko, R. I. Volkova, and V. P. Tikhonov, "Modulation of RBC volume distributions by oxidants (phenazine methosulfate and tert-butyl hydroperoxide): 
role of Gardos channel activation," Bioelectrochemistry, vol. 73, no. 1, pp. 49-54, 2008.

[38] T. H. Papanek, The Water Permeability of the Human Erythrocyte in the Temperature Range $+25^{\circ} \mathrm{C}$ to $-10^{\circ} \mathrm{C}$, Massachusetts Institute of Technology, Department of Mechanical Engineering, 1978.

[39] A. W. L. Jay, "Geometry of the human erythrocyte. I. Effect of albumin on cell geometry," Biophysical Journal, vol. 15, no. 3, pp. 205-222, 1975.

[40] F. W. Kleinhans, "Membrane permeability modeling: kedemkatchalsky vs a two-parameter formalism," Cryobiology, vol. 37, no. 4, pp. 271-289, 1998.

[41] I. I. Katkov, "A two-parameter model of cell membrane permeability for multisolute systems," Cryobiology, vol. 40, no. 1, pp. 64-83, 2000.

[42] P. B. Canham and A. C. Burton, "Distribution of size and shape in populations of normal human red cells." Circulation Research, vol. 22, no. 3, pp. 405-422, 1968.

[43] E. K. Hoffmann and P. B. Dunham, "Membrane mechanisms and intracellular signalling in cell volume regulation," International Review of Cytology, vol. 161, pp. 173-262, 1995.

[44] C. B. Bates and Naval Weapons Laboratory Dahlgren, The Chi-Square Test of Goodness of Fit for a Bivariate Normal Distribution, Defense Technical Information Center, 1966.

[45] A. K. Parpart, P. B. Lorenz, E. R. Parpart, J. R. Gregg, and A. M. Chase, "The osmotic resistance (fragility) of human red cells," Journal of Clinical Investigation, vol. 26, no. 4, pp. 636-640, 1947. 


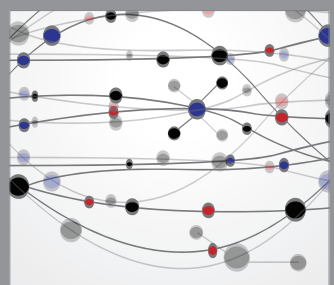

The Scientific World Journal
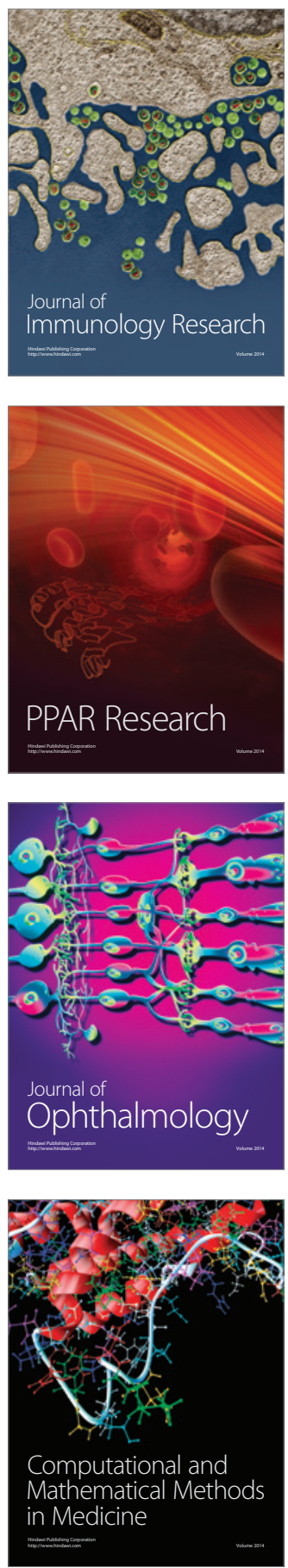

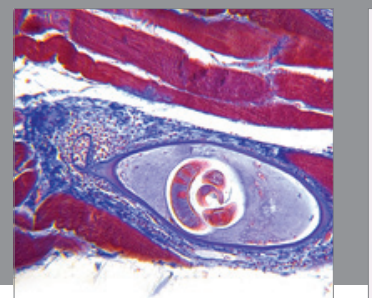

Gastroenterology

Research and Practice
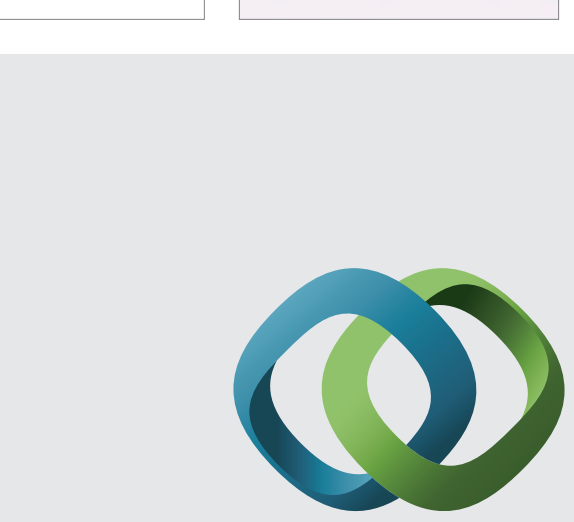

\section{Hindawi}

Submit your manuscripts at

http://www.hindawi.com
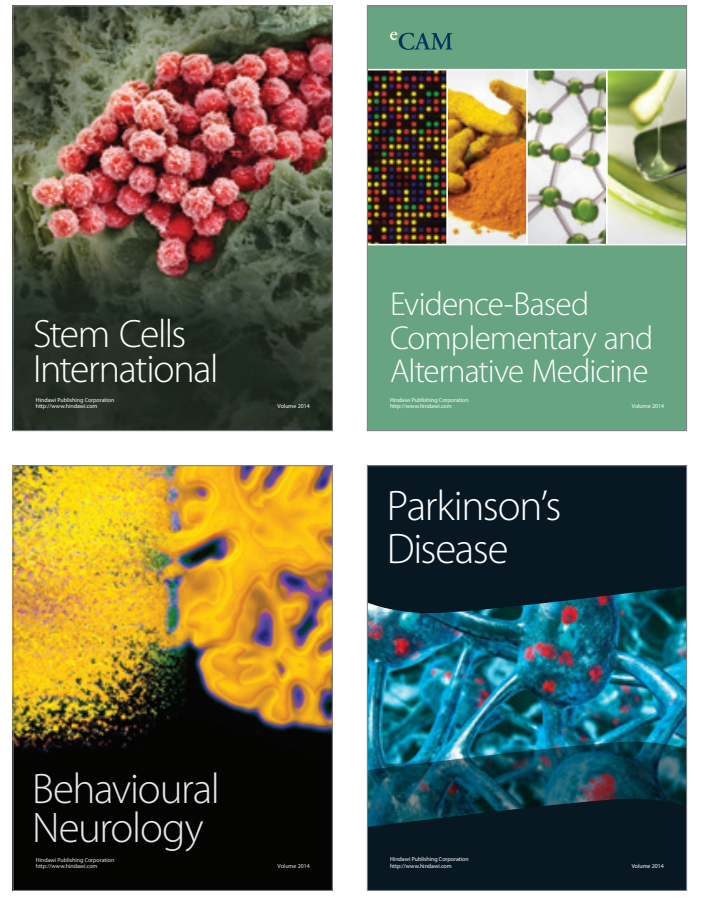
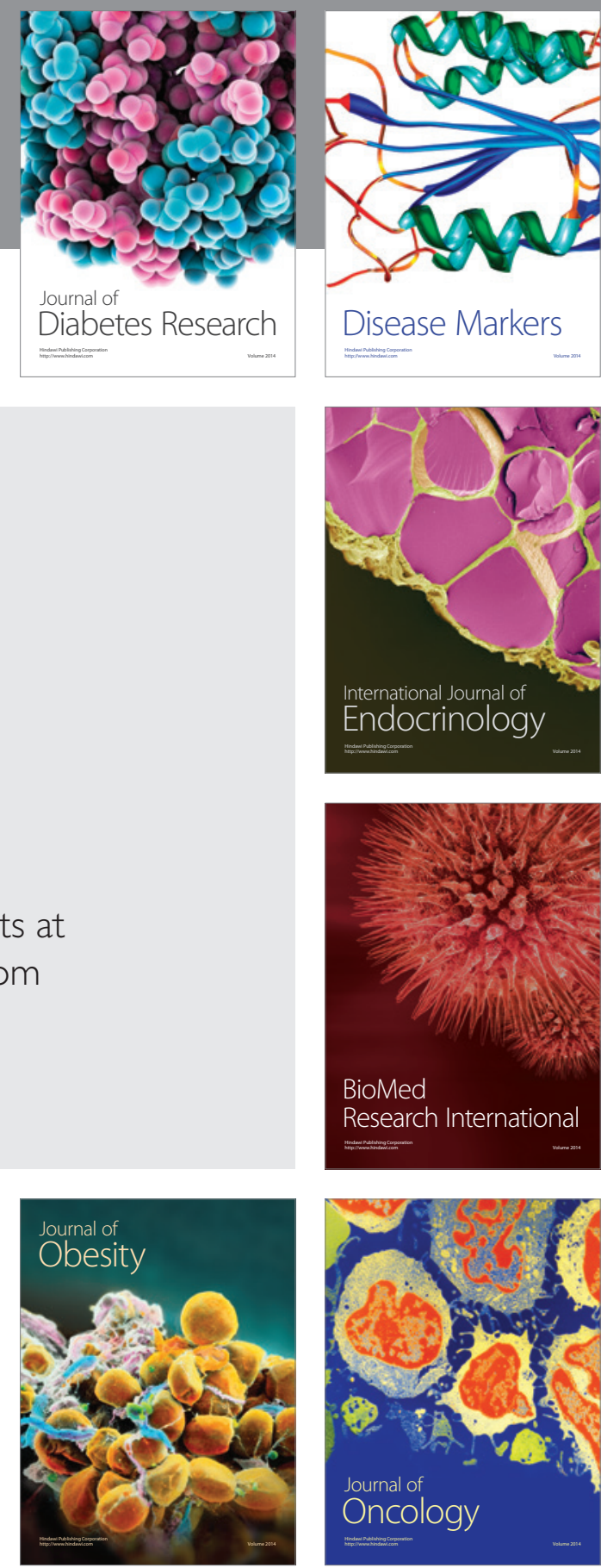

Disease Markers
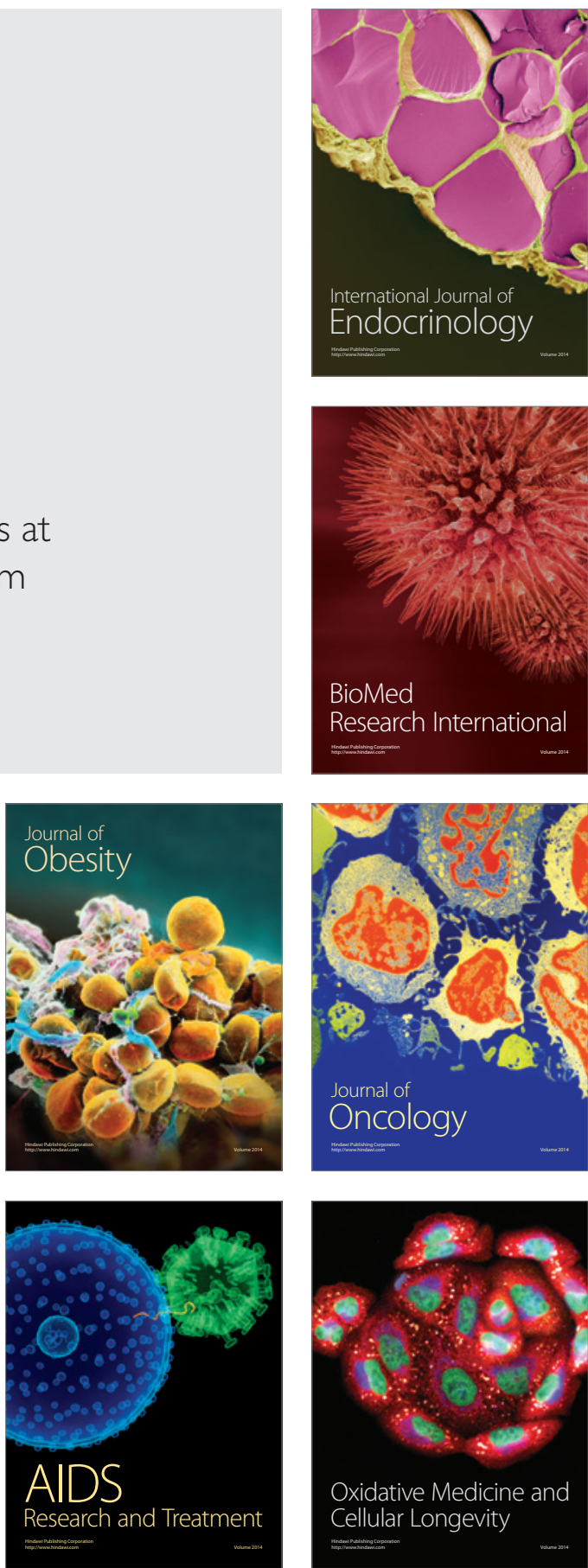